\title{
ELECTRICAL BREAKDOWN STUDIES WITH MYCALEX INSULATORS*
}

\author{
W. Waldron, W. Greenway, S. Eylon, E. Henestroza, S. Yu \\ Lawrence Berkeley National Laboratory, Berkeley, CA 94720, USA
}

\section{Abstract}

Insulating materials such as alumina and glassbonded mica (Mycalex) are used in accelerator systems for high voltage feedthroughs, structural supports, and barriers between high voltage insulating oil and the vacuum beam pipe in induction accelerator cells. Electric fields in the triple points should be minimized to prevent voltage breakdown. Mechanical stress can compromise seals and result in oil contamination of the insulator surface. We have tested various insulator cleaning procedures including ultrasonic cleaning with a variety of aqueous-based detergents, and manual scrubbing with various detergents. Water sheeting tests were used to determine the initial results of the cleaning methods. Ultimately, voltage breakdown tests will be used to quantify the benefits of these cleaning procedures.

\section{INTRODUCTION}

Glued Mycalex insulators have been used in the induction cells and the injector column of the second axis of the Dual Axis Radiographic Hydrodynamic Test (DARHT) facility at Los Alamos National Laboratory [1,2]. Mycalex samples were tested in vacuum to determine the electrode geometry and the acceptable fields at the insulator triple points. The effect of oil contamination on voltage holding, and cleaning methods have also been considered.

\section{HOCKEYPUCK TESTS}

\section{Test \#1}

The pulser used for these tests was an RC discharge circuit with a time constant of $24 \mathrm{~ms}$. In this configuration, the insulators were glued between "flowerpot" electrodes to lower the fields at the insulator triple points (Figure 1). For a peak test voltage of $90 \mathrm{kV}$, the peak field at the electrode is 125 $\mathrm{kV} / \mathrm{cm}$ (Figure 2). The observed voltage breakdowns around $90 \mathrm{kV}$ were between the two electrodes $\left(0.48^{\prime \prime}\right.$ gap) and not along the insulator surface. The electrodes did condition to hold $90 \mathrm{kV}$.

* This work has been performed under the auspices of the US DOE by UC-LBNL under contract DEAC03-76SF00098.

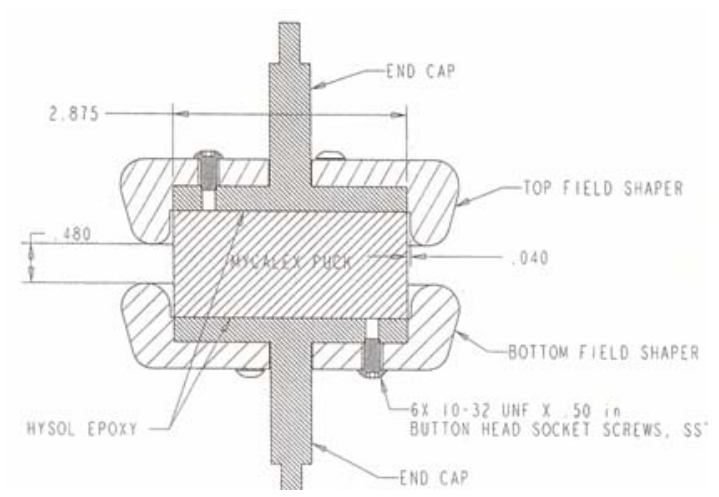

Figure 1: Test \#1 insulator and electrode configuration.

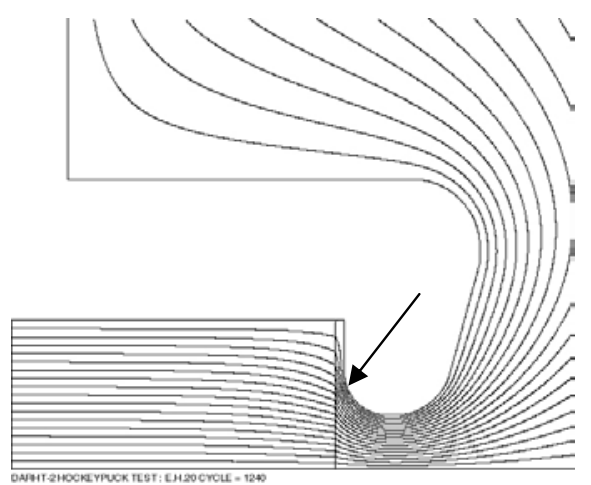

Figure 2: Test \#1 electric field distribution with the arrow pointing to the highest field region.

\section{Test \#2}

In this configuration, the insulators were glued between flat electrodes which created a uniform field of $30 \mathrm{kV} / \mathrm{cm}$ on the insulator surface for a $100 \mathrm{kV}$ test voltage. The insulator held above $100 \mathrm{kV}$ and there were no breakdowns.

\section{Test \#3}

In this configuration, the insulators were glued between rectangular electrodes which hung over the insulator sample to create a triple point with a field of $200 \mathrm{kV} / \mathrm{cm}$ for a $110 \mathrm{kV}$ test voltage (Figure 3 ). This sample was tested to $110 \mathrm{kV}$ without any voltage breakdowns. 


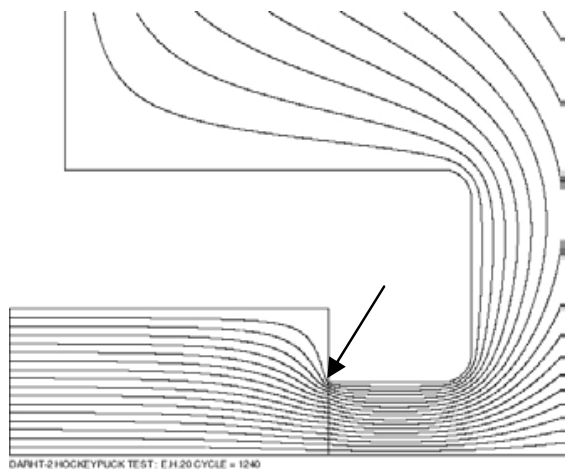

Figure 3: Test \#3 electric field distribution with the arrow pointing to the highest field region.

\section{Test \#4}

In this configuration, the insulators were glued between shaped electrodes which hung over the insulator sample to create a triple point with a field of $110 \mathrm{kV} / \mathrm{cm}$ for a $40 \mathrm{kV}$ test voltage (Figure 4). This sample broke down above $40 \mathrm{kV}$.

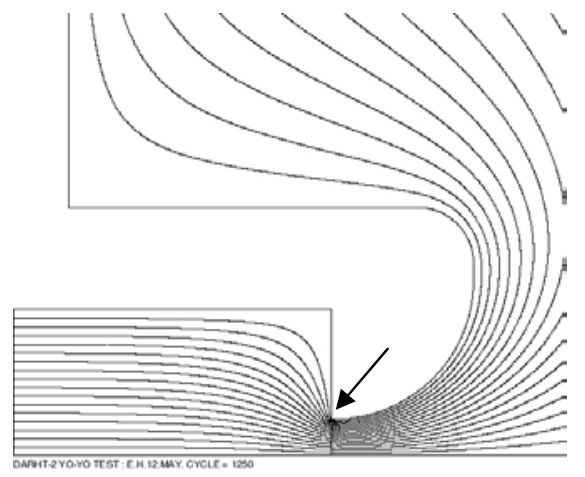

Figure 4: Test \#4 electric field distribution with the arrow pointing to the highest field region.

\section{CLEANING PROCEDURES}

A variety of cleaning methods were tested to remove Shell Diala AX transformer oil from Mycalex insulators. An in situ approach was developed for large insulators which are part of an assembly and an approach involving the removal, cleaning, and replacement was developed for small removable insulators. Aqueous-based cleaners were chosen for their ease of use, safety, and effectiveness $[3,4]$.

\section{Manual In Situ Procedure}

Contaminated insulator samples were scrubbed for three minutes with clean $3 \mathrm{M}$ Scotchbrite maroon pads that were wetted with the detergent being tested. During three minute cleaning cycles, additional detergent was added to the pad as needed to maintain effectiveness. After 3 minute cleaning cycles, the samples were rinsed with $18 \mathrm{Mohm}$ deionized water and checked for beading or sheeting on the surface. If beading was noted (oil still present on surface), the cycle was repeated until sheeting was present Sheeting of the $18 \mathrm{Mohm}$ deionized water was used as the main criteria for cleaning effectiveness. Fresh Best $\mathrm{N}$-Dex Nitril gloves and Scotchbrite pads were used for each cleaning cycle to eliminate cross contamination. Pads were not dipped in detergent mix but were sprayed to eliminate cross contamination. Detergents were heated to approximately 135 degrees $\mathrm{F}$ for the cleaning cycle. The Wyndotte 909 detergent was more effective than the Metalube BlueGold detergent and the VWR Labtone detergent. On average, the Wyndotte 909 detergent took three cleaning cycles compared to four cleaning cycles for the other detergents.

\section{Ultrasonic Cleaning Procedure}

The contaminated insulator samples were placed in a beaker with heated detergent and run for 15-30 minutes in the ultrasonic bath. After the cleaning cycle, the samples were removed with tongs and rinsed with deionized water and checked for sheeting. The cycle was repeated until sheeting was noted on sample. As before, the Wyndotte 909 detergent was more effective than the Metalube BlueGold detergent and the VWR Labtone detergent. On average, three cleaning cycles were required using the Wyndotte 909 detergent.

\section{FUTURE HIGH VOLTAGE TESTS}

Grade 400 Mycalex cylinders and cones have been purchased and will be tested for voltage breakdown after the various cleaning procedures have been performed. The cylinders have a 1" diameter and are $1 "$ tall. The cones are 1" tall and have a 3.75" diameter on one end and 0.6" diameter on the other end. The surface of the cone is at a 30 degree angle. Cylinders and cones will be tested to quantify the "angle effect" on voltage holding. Using a $50 \mathrm{ohm}$ thyratronswitched pulse forming network into a 1:8 step-up transformer with a matched resistive load, high voltage testing will be done to quantify the benefits of the various cleaning procedures. The maximum test voltage is $160 \mathrm{kV}$ for a $700 \mathrm{~ns}$ pulse (FWHM) (Figure 5). $160 \mathrm{kV}$ will produce peak fields of $63 \mathrm{kV} / \mathrm{cm}$ on the cylindrical sample and $260 \mathrm{kV} / \mathrm{cm}$ on the conical sample. Voltage flashovers across the insulator surface will be detected using the voltage waveforms and the vacuum gauge. 


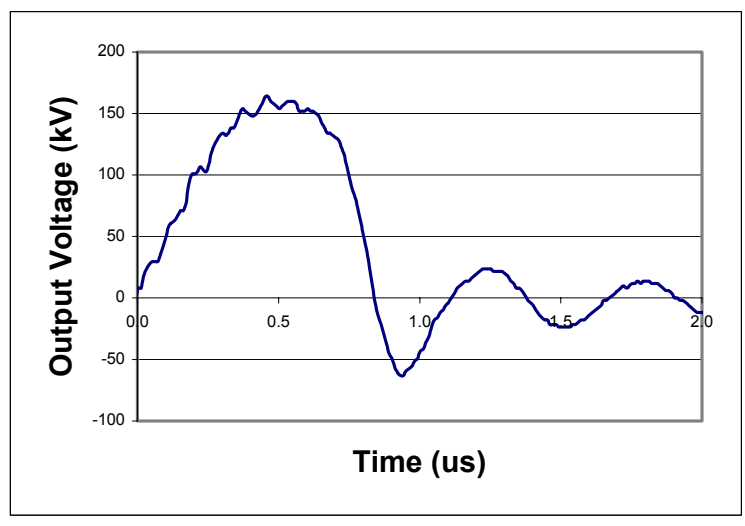

Figure 5: Output voltage for breakdown tests.

These insulators will be contaminated with Shell Diala AX transformer oil and will be cleaned using the various procedures. The insulators will then be glued to stainless steel disks using Hysol EA 9359.3 epoxy. By gluing the insulators to these "disposable" disks which insert into the high voltage electrodes, the need to polish the large electrodes between insulator tests will be eliminated (Figures 6 and 7). This configuration also tests the performance of insulator glue lines.

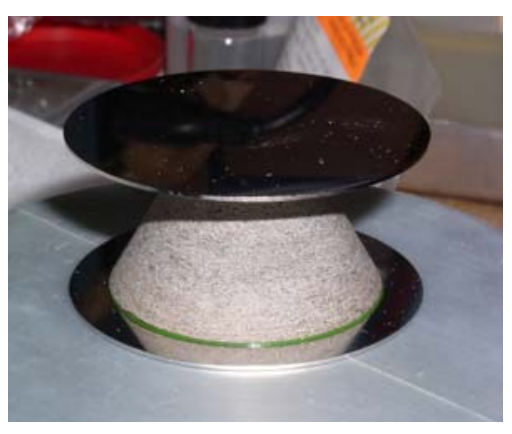

Figure 6: Mycalex cone glued to "disposable" stainless steel disks.

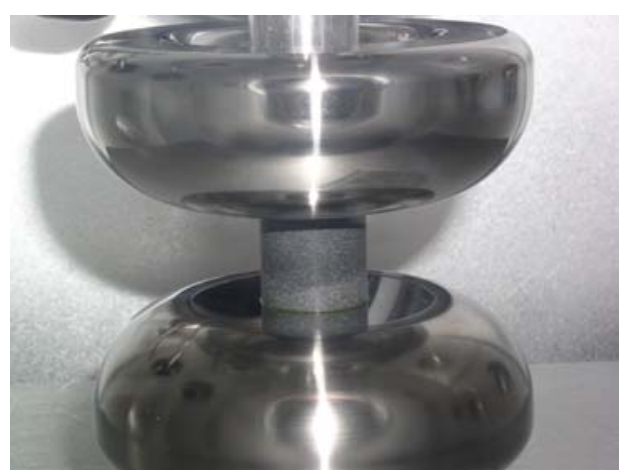

Figure 7: Mycalex cylinder between test electrodes.

\section{CONCLUSION}

In the most successful geometries, the Mycalex hockeypuck insulators achieved between $110 \mathrm{kV} / \mathrm{cm}$ and $200 \mathrm{kV} / \mathrm{cm}$ fields at the insulator triple points without voltage breakdown. These numbers were unexpectedly high and may not hold when tested for better statistics. Both manual and ultrasonic insulator cleaning procedures after oil contamination were established. Wyndotte 909 detergent was the most effective per the sheeting tests. Future high voltage breakdown tests will quantify the electrical benefits of the various cleaning methods.

\section{REFERENCES}

[1]C. Ekdahl et al., "DARHT II Commissioning Results", proceedings from this conference.

[2] Mycalex is the trade name for glass-bonded mica made by Spaulding Composites Co.

[3] J. Shoemaker et al., LLNL report UCRL-ID-115831 (1994).

[4] J. Geurtin, internal LBNL document (1994). 